\title{
Nanofibrous Membrane Dressings Loaded With Sodium Hydrogen Sulfide/Endothelial Progenitor Cells Promote Wound Healing
}

\author{
Jie Lian ${ }^{1+}$, Guanqun $\mathrm{Ju}^{2+}$, Xueyao Cai ${ }^{1}$, Yuchen $\mathrm{Cai}^{1}$, Chun $\mathrm{Li}^{3}$, Sunxiang $\mathrm{Ma}^{1 *}$ and \\ $\mathrm{YiCaO}^{1 *}$
}

'Department of Plastic and Reconstructive Surgery, Shanghai Ninth People's Hospital, Shanghai Jiao Tong University School of Medicine, Shanghai, China, ${ }^{2}$ Department of Urology, Changzheng Hospital, Naval Medical University, Shanghai, China,

${ }^{3}$ Key Laboratory of Functional Genomic and Molecular Diagnosis of Gansu Province, Lanzhou, China

OPEN ACCESS

Edited by:

Masoud Mozafari,

University of Toronto, Canada

Reviewed by:

Baolin Guo,

X'an Jiaotong University, China

Alexander E. Berezin,

Zaporizhia State Medical

University, Ukraine

*Correspondence:

Sunxiang $\mathrm{Ma}$

msunxiang@163.com

Yi CaO

evacao0102@yahoo.com

tThese authors have contributed equally to this work

Specialty section:

This article was submitted to Biomaterials,

a section of the journal Frontiers in Bioengineering and Biotechnology

Received: 23 January 2021

Accepted: 07 June 2021

Published: 04 August 2021

Citation:

Lian J, Ju G, Cai X, Cai Y, Li C, Ma S and Cao Y (2021) Nanofibrous Membrane Dressings Loaded With Sodium Hydrogen Sulfide/Endothelial

Progenitor Cells Promote Wound

Healing.

Front. Bioeng. Biotechnol. 9:657549. doi: 10.3389/fbioe.2021.657549
Hydrogen sulfide $\left(\mathrm{H}_{2} \mathrm{~S}\right)$ has been identified as an important gasotransmitter. $\mathrm{H}_{2} \mathrm{~S}$ donor can release $\mathrm{H}_{2} \mathrm{~S}$ sustained and is used as wound dressing. Endothelial progenitor cells (EPCs), given their regenerative ability, have also been reported to enhance wound healing. However, effective drug carriers are missing for the clinical application of $\mathrm{H}_{2} \mathrm{~S}$ and EPCs. In this study, we investigated a novel drug carrier nanofibrous membrane, which was prepared by blending the recombinant spider silk protein (rMaSp) and sodium hydrogen sulfide (NaHS) by electrospun. Our results show that the rMaSp/NaHS nanofibrous membrane is associated with high hemocompatibility and cytocompatibility and is capable of stably releasing $\mathrm{H}_{2} \mathrm{~S}$ for a long period of time. We also tested the $\mathrm{rMaSp} / \mathrm{NaHS}$ membrane loaded with EPCs in an in vivo cutaneous wound model. We showed that the $\mathrm{rMaSp} / \mathrm{NaHS} / \mathrm{EPC}$ system significantly enhances wound regeneration efficiency as compared to rMaSp membrane and $\mathrm{rMaSp} / \mathrm{NaHS}$ membrane. This study provides key evidence supporting the clinical application of nanofibrous membrane in the field of skin tissue regeneration.

Keywords: sustained-releasing, $\mathrm{H}_{2} \mathrm{~S}$, nanofibrous membrane, endothelial progenitor cells, wound healing

\section{INTRODUCTION}

Hydrogen sulfide $\left(\mathrm{H}_{2} \mathrm{~S}\right)$, which plays important roles in inflammation, reperfusion injury, and circulatory shock of cardiovascular and nervous systems, can rapidly travel through the cell membranes to exert its biological effects, resulting in multiple cytoprotective responses, such as anti-inflammation, relaxing vascular, stimulating angiogenesis, and attenuating oxidative-stressrelated tissue injuries (Wu et al., 2016). $\mathrm{H}_{2} \mathrm{~S}$ protects fibroblast cells from $\mathrm{H}_{2} \mathrm{O}_{2}$-induced oxidative damage and promotes expressions of wound healing-related genes in vitro (Feng et al., 2015). In vitro and in vivo studies have shown that $\mathrm{H}_{2} \mathrm{~S}$ promotes the proliferation and migration of vascular endothelial cells, the formation of microvessels, and wound healing (Papapetropoulos et al., 2009; Wallace et al., 2009; Altaany et al., 2013). As $\mathrm{H}_{2} \mathrm{~S}$ precursors, sodium hydrogen sulfide (NaHS) or sodium sulfide $\left(\mathrm{Na}_{2} \mathrm{~S}\right)$ has been used as an ingredient to prepare biomaterial for wound healing. Due to the multiple physiological functions of $\mathrm{H}_{2} \mathrm{~S}$, the biomaterials loaded with $\mathrm{H}_{2} \mathrm{~S}$ donors capable of sustained release of $\mathrm{H}_{2} \mathrm{~S}$ have a good application prospect. Because of the aforementioned physiological of $\mathrm{H}_{2} \mathrm{~S}$, biomaterials loaded with $\mathrm{H}_{2} \mathrm{~S}$ donors have a good application prospect. Many 
studies have been using NaHS to release $\mathrm{H}_{2} \mathrm{~S}$ in the presence of water. However, the lifetime of NaHS is short, making it difficult to maintain a constant cellular concentration of $\mathrm{H}_{2} \mathrm{~S}$ over a prolonged period. In order to provide sustained releasing of $\mathrm{H}_{2} \mathrm{~S}$, it is necessary to find a suitable biomaterial as a carrier. Endothelial progenitor cells (EPCs) are vascular EPCs, which can secrete a variety of vascular factors to promote vascular repair and regeneration and can also participate in vascular regeneration (Asahara et al., 1997; Lin et al., 2000). Therefore, EPCs have been used to enhance wound healing (Kim et al., 2009; Asai et al., 2013).

Spider silk, known for their strength, toughness, good elasticity, and biocompatibility, can be used as promising biomaterials, showing a wide range of applications in the field of biotechnology and biomedicine (Omenetto and Kaplan, 2010). Among them, MaSp1, which is the main component protein of dragline silk with the best comprehensive performance, has attracted much attention in the research of medical materials. Because natural spider silk cannot be farmed due to the cannibalistic habits, strong territorial awareness, and limited silk production of most spiders, recombinant spider silk protein obtained from bioengineering served as an ideal substitute. It is worth mentioning that some functional amino sequences can be fused with the repetitive modules endowing the recombinant silk protein novel biomedical properties and expanding their applications in skin regeneration, and cell and tissue engineering (Andersson et al., 2017; Resch et al., 2018; Baklaushev et al., 2019). Furthermore, recombinant spider silk protein can be made from biomaterials with different processing methods, including electrospinning, which can prepare nanoscale fibers with high porosity, large specific surface area, high degree of fineness, and uniformity of fibers. Electrospun nanofibrous membranes from recombinant spider silk protein have high application potential in the biomedical field (Putzu et al., 2019).

In this study, the nanofibrous membrane was electrospun from the recombinant spider silk protein blended with $\mathrm{NaHS}$ as $\mathrm{H}_{2} \mathrm{~S}$ donor, exhibiting sustained releasing of $\mathrm{H}_{2} \mathrm{~S}$. The membrane was loaded with EPCs and employed as a novel wound dressing system to enhance wound regeneration. The wound healing effects were assessed using a full-thickness cutaneous wound model with $\mathrm{BALB} / \mathrm{c}$ male mice. We found that nanofibrous membrane-loaded NaHS/EPCs significantly enhanced wound healing by releasing $\mathrm{H}_{2} \mathrm{~S}$ and EPCs.

\section{MATERIALS AND METHODS}

\section{Preparation of Recombinant Spider Silk Protein}

The rMaSp and recombinant spider silk were obtained by the method as described in the previous literature. The construction of rMaSp is composed of a $6 \times$ His tag and six units consisting of two repeated polyalanine and glycine-rich regions derived from MaSp1 of Elsinoë australis (Andersson et al., 2017). In brief, the polyalanine- and glycine-rich regions were transferred into BL21 (DE3) Escherichia coli cells that were cultured overnight in Luria broth (LB) media at $37^{\circ} \mathrm{C}, 200 \mathrm{rpm}$. Then, the E. coli was then cultured in a $1 / 100$ inoculation of $500 \mathrm{ml} \mathrm{LB}$ media at $30^{\circ} \mathrm{C}$, $180 \mathrm{rpm}$, until $\mathrm{OD}_{600}$ reached $0.6-0.8$. E. coli cells were finally induced by adding isopropylthiogalactoside to a concentration of $0.3 \mathrm{mM}$. Then, the $E$. coli cells were cultured overnight at $20^{\circ} \mathrm{C}, 180 \mathrm{rpm}$, and harvested by centrifugation for $20 \mathrm{~min}, 5,000$ $\mathrm{rpm}$ at $4^{\circ} \mathrm{C}$. The pellets were resuspended in $20 \mathrm{mM}$ Tris $\mathrm{pH}$ 8 and lysated immediately with a sonicator. Then, the lysate was centrifuged at $12,000 \mathrm{rpm}$ at $4^{\circ} \mathrm{C}$ for $30 \mathrm{~min}$. Supernatants were loaded on a Ni-NTA column, and the protein was eluted with $300 \mathrm{mM}$ imidazole. The eluted protein solution was dialyzed against $20 \mathrm{mM}$ Tris $\mathrm{pH}$, at $4^{\circ} \mathrm{C}$ overnight. SDS-PAGE (10\%) and Coomassie Brilliant Blue staining were used to determine the protein purity.

\section{Electrospinning of Nanofibrous Membrane With $\mathrm{H}_{2} \mathrm{~S}$ Donor}

Hydrogen sulfide donor, NaHS, bought from Shandong Borman Chemical Co., Ltd., China. NaHS was dissolved in $1 \mathrm{mg} / \mathrm{ml}$ ethanol. Recombinant spidroin was dissolved in 1,1,1,3,3,3hexafluoro-2-propanol (HFIP, Shanghai Jizhi Biochemical Technology Co., Ltd., China) to form an $8 \% \mathrm{w} / \mathrm{v}$ spinning dope, then different weights of NaHS $(3.125,6.25,12.5,25$, and $50 \mu \mathrm{g} / \mathrm{ml}$ ) were added to prepare samples with $\mathrm{H}_{2} \mathrm{~S}$ donors, and finally, the concentration of rMaSp in all samples were adjusted to $10 \%(\mathrm{w} / \mathrm{w})$. The nanofibrous membrane was obtained by a homemade electrospinning system through the stationary collector described earlier with a flow rate at $0.6 \mathrm{ml} / \mathrm{h}$, voltage of $10 \mathrm{kV}$, and $50 \%$ humidity.

\section{Fiber Characterization}

The morphology of the nanofibrous membrane was scanned with a Quanta FEG250 scanning electron microscopy (FEI, Michigen, USA). The fiber samples were dried under nitrogen flow and then coated with gold. Three areas were randomly selected to test the uniformity of the fibers in each sample.

To analyze the Fourier transform infrared spectroscopy (FTIR) spectrum of dried rMaSp membrane and $\mathrm{rMaSp} / \mathrm{NaHS}$ membrane, the Nicolet 5700 Fourier transform infrared spectrometer was used with a spectral range of 4,000-676 $\mathrm{cm}^{-1}$, the scanning time of 32 , and the resolution of 0.04 wavenumber/cm.

Hemolysis assays of the nanofibrous membrane were performed according to the previous literature and performed as follows: Before the experiment, strips of the nanofibrous membrane $(10 \times 30 \mathrm{~mm})$ were sterilized in $75 \%$ ethanol for $0.5 \mathrm{~h}$ and then washed three times with sterile water. In brief, healthy red blood cells (HRBCs) were harvested from fresh white rabbit suspending in $3.8 \%$ sodium citrate (the ratio of sodium citrate to distilled water is $3.8: 100 \mathrm{w} / \mathrm{v}$ ) and centrifuged at 1,200 rpm for $10 \mathrm{~min}$, to harvest serum-free HRBCs. The pure HRBCs were washed 5 times with phosphate-buffered saline (PBS) and then diluted 10 times in PBS before hemolysis assays. The diluted HRBCs $(0.2 \mathrm{ml})$ were mixed with $10 \mathrm{ml}$ deionized water as a positive control and $10 \mathrm{ml}$ PBS buffer solution as a negative control. After gentle shaking, all nanofibrous membranes were incubated at $37^{\circ} \mathrm{C}$ for $2 \mathrm{~h}$ and centrifuged at 2,000 rpm for $5 \mathrm{~min}$. The supernatant was carefully removed. The absorbance 
of the supernatant was measured at $545 \mathrm{~nm}$ using an UV-visible spectrophotometer (PerkinElmer, Massachusetts, USA). The formula for calculating the hemolysis ratio is as follows:

$$
H R=(S A-N A) /(P A-N A) \times 100 \%
$$

where $S A, P A$, and $N A$ represent the absorbance of the experimental sample, positive control, and negative control, respectively. The assays were repeated three times to ensure reproducibility.

\section{Test the Mechanical Properties of Nanofibrous Membranes}

The mechanical properties of nanofibrous membranes were examined by a universal material tester H5K-S (Hounsfield, England) with a crosshead speed of $30 \mathrm{~mm} / \mathrm{min}$ and a gauge length of $30 \mathrm{~mm}$. All the nanofibrous membranes were cut into strips $(50 \times 10 \mathrm{~mm})$, in which four random strips of each fibrous membrane were tested to calculate the stress and strain of the nanofibrous membranes according to the previous literature (Hong et al., 2011).

\section{Detect the Wettability of the rMaSp or rMaSp/NaHS Membrane}

Wettability of the nanofibrous membranes was determined from water contact angles measured with a drop shape analyzer Kyoma G-1 and the sessile drop technique. All data were analyzed with ADVANCE-drop shape software to determine the contact angles. Both membranes consist of three samples, and each sample test was repeated three times.

\section{Testing the Water Vapor Transmittance of the rMaSp or rMaSp/NaHS Membrane}

The water vapor transmittance (WVTR) of the rMaSp or $\mathrm{rMaSp} / \mathrm{NaHS}$ membrane in contact with water vapor was determined according to the pharmaceutical industry standard YY/T 0471.2-2004 of the People's Republic of China. The membrane film to be tested is encapsulated in the opening of the moisture permeable cup filled with deionized water, and the lower surface of the film is in contact with the opening of the cup. Then, it is placed in a constant temperature and humidity box with $37 \pm 1^{\circ} \mathrm{C}$ and relative humidity (RH) of $20 \%$. After a period of time, weigh the samples and measure the moisture permeability. There are five samples in each group, and the average value of the results is calculated by the following formula:

$$
W \operatorname{VTR}\left(g / m^{2} / \text { day }\right)=(W 1-W 2) / A \times t \times 24 \times 10^{6}
$$

where $\mathrm{W} 1$ is the mass before the test $(\mathrm{g})$, W2 is the mass after the test ( $\mathrm{g}), A$ is the effective area of the moisture permeable cup $\left(\mathrm{mm}^{2}\right)$, and $t$ is the test time $(\mathrm{h})$.

\section{The Antibacterial Properties of rMaSp Membrane and $\mathrm{rMaSp} / \mathrm{NaHS}$ Membrane}

Soak a diameter of $1.5 \mathrm{~cm}$ of rMaSp membrane or $\mathrm{rMaSp} / \mathrm{NaHS}$ membrane totally in $75 \%$ ethanol for $5 \mathrm{~min}$, then dry the membranes, and put them on the agar plate. At the same time,
$0.2 \mathrm{ml}$ of E. coli or Staphylococcus aureus that cultured overnight was inoculated in the center of the membrane and cultured at $37^{\circ} \mathrm{C}$ for 7 days.

\section{Profile of $\mathrm{H}_{2} \mathrm{~S}$ Release}

Release kinetics of $\mathrm{H}_{2} \mathrm{~S}$ from nanofibrous membrane was measured according to the previous study (Paul and Snyder, 2015; Lin et al., 2017). A total of $20 \mathrm{mg}$ of membrane was immersed in $50 \mathrm{ml}$ PBS (pH 7.4). To minimize the volatilization loss, the membranes were separately prepared and conducted for each test time point in $48 \mathrm{~h}$. Then, the membranes were sealed with Tegaderm ${ }^{\mathrm{TM}}$ at $33^{\circ} \mathrm{C}$ and then withdrawn periodically at prescribed time intervals. Reaction aliquots $(0.5 \mathrm{ml})$ were added to the mixture of zinc acetate $\left(50 \mu \mathrm{L}, 1 \% \mathrm{w} / \mathrm{v}\right.$ in $\left.\mathrm{H}_{2} \mathrm{O}\right)$ and $\mathrm{NaOH}(6.25 \mu \mathrm{L}, 1.5 \mathrm{M})$ in $1.5 \mathrm{ml}$ centrifuge tubes at certain time intervals. Then the solution was centrifuged at 20,500 RCF for $1 \mathrm{~h}$, followed by removing the supernatant using a pipette. $\mathrm{FeCl}_{3}(100 \mu \mathrm{L}, 30 \mathrm{mM}$ in $1.2 \mathrm{M} \mathrm{HCl})$ and $N, N$-dimethylp-phenylenediamine sulfate $(100 \mu \mathrm{L}, 20 \mathrm{mM}$ in $7.2 \mathrm{M} \mathrm{HCl})$ were added to the centrifuge tubes. Finally, the solutions were transferred into a 96-well microplate followed by the addition of $1 \mathrm{ml}$ water, and the absorbance $(670 \mathrm{~nm})$ was taken after $20 \mathrm{~min}$.

\section{Cell Lines and Cell Cultures}

The NIH 3T3 cells of the mouse fibroblast cell line were purchased from the American Type Culture Collection, USA, and the mouse EPCs were purchased from the Shanghai Institute of Biochemistry and Cell Biology, Chinese Academy of Sciences, China. The cells were maintained in Dulbecco's Modified Eagle's Medium (DMEM, Sigma-Aldrich, Missouri, USA) supplemented with $10 \%$ heat-inactivated fetal bovine serum (HyClone, Thermo Scientific, Missouri, USA), $100 \mathrm{U} / \mathrm{ml}$ penicillin, and $100 \mu \mathrm{g} / \mathrm{ml}$ streptomycin (Gibco BRL, Invitrogen Corp., Carlsbad, CA, USA). They were cultured in a $5 \% \mathrm{CO}_{2}$ humidified incubator at $37^{\circ} \mathrm{C}$. Then, they were trypsinized and seeded on the sterilized rMaSp or $\mathrm{rMaSp} / \mathrm{NaHS}$ nanofibrous membrane with a cell density of $5 \times 10^{3}$ cells per $\mathrm{cm}^{2}$.

\section{Cell Viability Assay}

CCK-8 assays were performed to evaluate the cytocompatibility of $\mathrm{rMaSp}$ or $\mathrm{rMaSp} / \mathrm{NaHS}$ nanofibrous membranes. At each test time point, $12,24,48$, and $72 \mathrm{~h}$, the culture medium was removed, the membranes were washed with PBS, and the fresh medium was added into the wells. Then, the CCK- 8 assays were operated according to the protocol of the manufacturer. Each measurement was repeated three times.

\section{Animal Cutaneous Model for Wound Healing}

Male BALB/c mice (Jiesijie Experimental Animal Co., Ltd., China) weighing $20 \pm 3 \mathrm{~g}$ were treated strictly in accordance with the International Ethical Guidelines and the National Institutes of Health Guide concerning the Care and Use of Laboratory Animals. The mouse was anesthetized with $4 \%$ chloral hydrate, and the skin was cleaned with the back skin exposed. Silicone rings with an internal diameter of $8 \mathrm{~mm}$ and a thickness of $0.5 \mathrm{~mm}$ were stitched on the skin. Two full-thickness wounds 


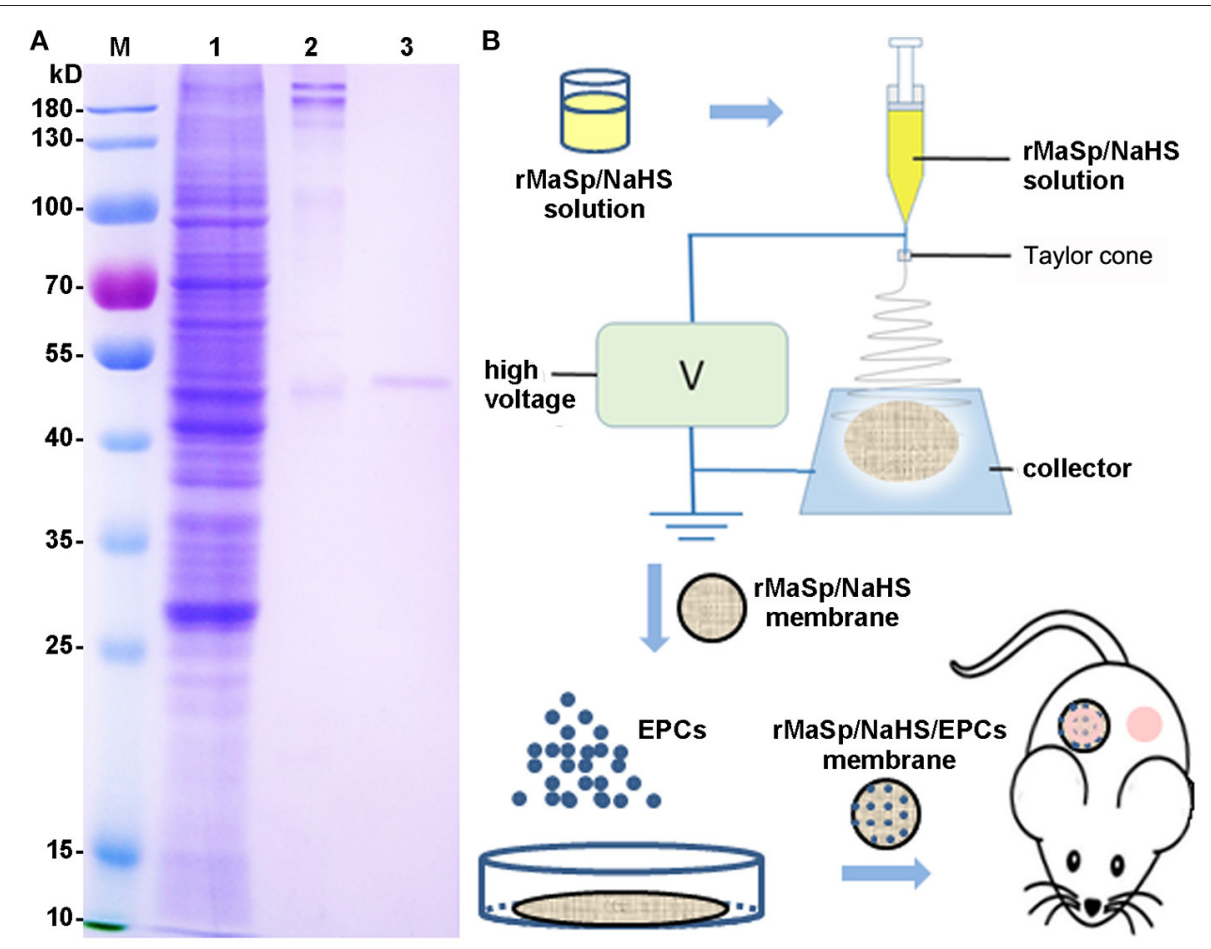

FIGURE 1 | Preparation of recombinant spider silk protein (rMaSp) and the schematic diagram of wound healing program. (A) Coomassie Brilliant Blue staining of rMaSp purification. Lanes of w1-3 are protein ladder, supernatant of lysate, precipitation of lysate, rMaSp, respectively. (B) The schematic diagram of wound healing program with rMaSp/sodium hydrogen sulfide (NaHS)/endothelial progenitor cell (EPC) membrane.

per mice were created on their mid-back with a 6-mm diameter puncher (Acuderm ${ }^{\circledR}$ Inc., Ft Lauderdale, FL, USA).

For the rMaSp/NaHS/EPC group, all operations were performed under sterile conditions. First, the rMaSp/NaHS/EPC membrane was prepared on the sterile round cover glass with a diameter of $2 \mathrm{~cm}$. Then, the cover glass was placed on the bottom of a $3-\mathrm{cm}$ cell culture dish. Finally, $1 \times 10^{5}$ EPCs were inoculated in each culture dish. After cultured for $48 \mathrm{~h}$, the cover glass and the $\mathrm{rMaSp} / \mathrm{NaHS} / \mathrm{EPC}$ membrane were carefully separated with tweezers. The $\mathrm{rMaSp} / \mathrm{NaHS} / \mathrm{EPC}$ member was immediately transplanted to experimental animals. After the $\mathrm{rMaSp} / \mathrm{NaHS} / \mathrm{EPC}$ membrane covered the wound, the mice were sealed and bandaged with sterile gauze. Mice were fed in the sterile mouse feeding room, and EPCs can survive in the environment provided by the mouse subcutaneous tissue under aseptic conditions. The optical photographs of each wound were taken. RMaSp, rMaSp/NaHS (10\% w/w NAHS to RMASP), and $\mathrm{rMaSp} / \mathrm{NaHS} / \mathrm{EPC}$ with a diameter of $7 \mathrm{~mm}$ were deposited in wound areas. Wounds were covered with medical bandages. After transplantation, the photos of general wound areas were taken on days 7,14 , and 20 and analyzed with the ImageJ software. The ratio of wound healing was calculated as follows:

$$
C(\%)=\frac{C_{0}-C_{f}}{C_{0}} \times 100 \%
$$

where $C \%$ is the wound healing closure ratio, $C_{0}$ is the original wound area, and $C_{\mathrm{f}}$ is the open area on point day.

\section{Hematoxylin-Eosin Staining}

The skin histological analysis was performed according to the previous literature on days 7 and 20 after transplantation. After anesthesia of the mice, the wound skin tissues were excised, maintained in cold $4 \%$ paraformaldehyde in $0.01 \mathrm{M}$ PBS ( $\mathrm{pH}=7.4$ ) overnight, embedded in paraffin, and cut into 5- $\mu \mathrm{m}$ thick sections with microtomes (LEICA RM2235, Germany). Four wound skin areas were analyzed at each time point.

The wound skin was stained with hematoxylin and eosin (H\&E) (Beyotime Institute of Biotechnology, China) for morphological evaluation. The sections were put in the xylene for $20 \mathrm{~min}, 100 \%$ alcohol for $5 \mathrm{~min}, 95 \%$ alcohol, and $80 \%$ alcohol for $2 \mathrm{~min}$, distilled water for $5 \mathrm{~min}$, hematoxylin nuclear stain for $5 \mathrm{~min}$, and PBS washed for $3 \mathrm{~min}$ to remove the extra H\&E staining in the extracellular matrix for $2 \mathrm{~min}$. Then, the slices were washed with deionized water for $5 \mathrm{~min}$, the sections were dehydrated through increasing concentration of ethanol and xylene, and sealed with neutral resin. The photographs were taken with a Nikon microscope (Nikon, Tokyo, Japan).

\section{Evaluation of Deposit Collagen on Wound Skin}

Collagen deposition was measured by the insoluble collagen assay according to the previous literature (Wirohadidjojo et al., 2011). A 5-mg tissue of each wound skin was cut from the wound 

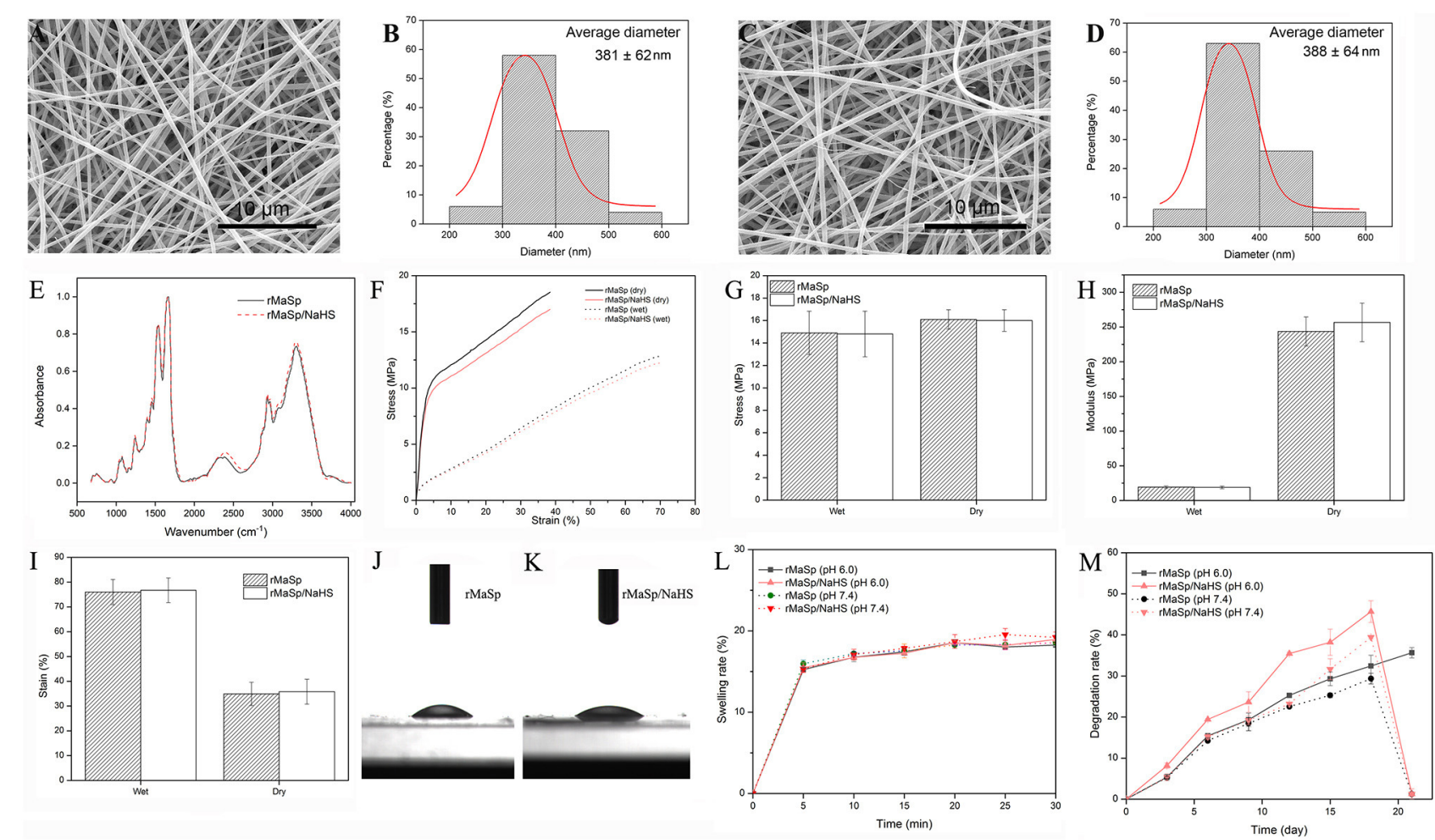

FIGURE 2 | Characterization of nanofibrous membrane. The SEM images of rMaSp (A) and rMaSp/NaHS membrane (C) and diameter distribution of rMaSp (B) and rMaSp/NaHS nanofibers (D). The Fourier transform infrared spectroscopy spectrum of dried rMaSp membrane and rMaSp/NaHS membrane (E). The mechanical properties of dry and wet rMaSp/NaHS membrane (F-I). The water droplets on the rMaSp (J) or rMaSp/NaHS membrane surfaces (K). The swelling capacity of rMaSp or rMaSp/NaHS membrane (L). The degradation profile of rMaSp or rMaSp/NaHS membrane (M).
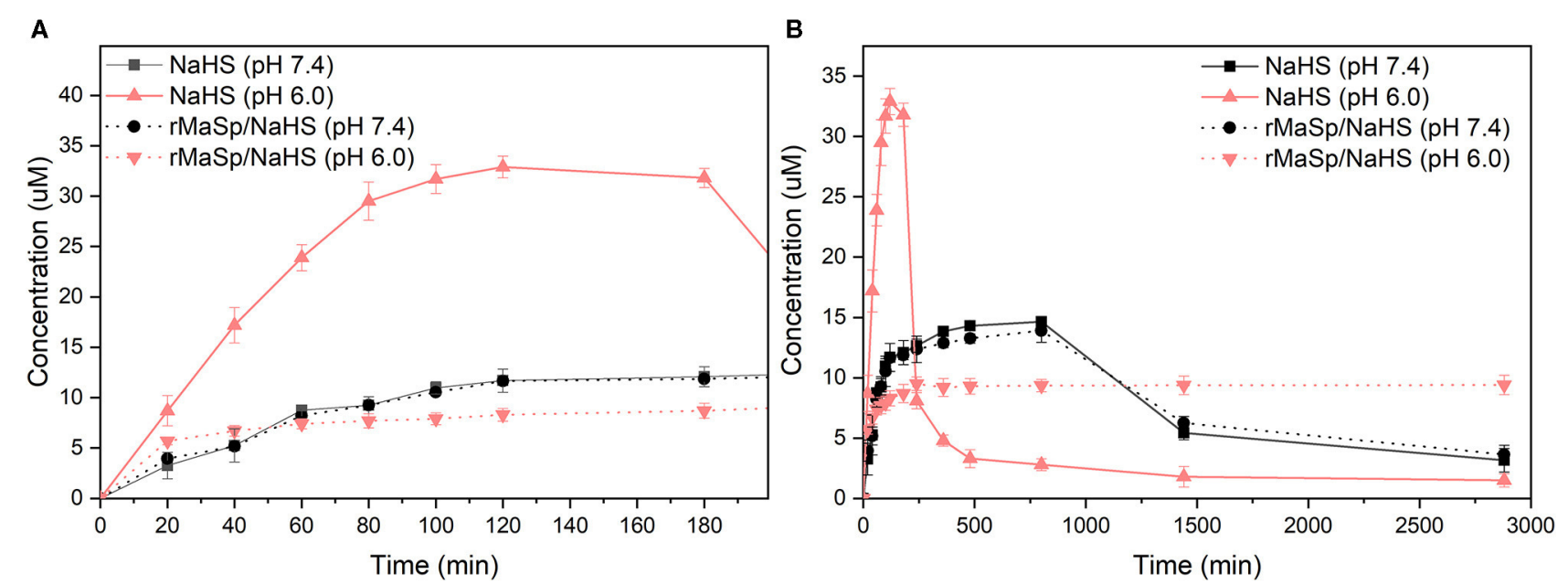

FIGURE $3 \mid \mathrm{H}_{2} \mathrm{~S}$ releasing kinetics of donor NaHS vs. rMaSp/NaHS fiber (with 10\% NaHS) under pH 7.4. (A) Short-term releasing profile (0-180 min). (B) Longer-term releasing profiles $(0-2,880 \mathrm{~min})$.

areas and put in a 96-well plate. After washed with PBS, the tissues were fixed with Bouin solution for $1 \mathrm{~h}$ and rinsed with tap water until all the yellow color was completely removed. Then the tissues were dried at room temperature overnight. A $200-\mu \mathrm{L}$
Sirius Red diluted in saturated picric acid was added for $1 \mathrm{~h}$. Then the unbinding Sirius Red was washed with $200 \mu \mathrm{L}$ of $0.1 \mathrm{~N} \mathrm{HCl}$. Sirius Red on the well bases was then removed by dilution with $200 \mu \mathrm{L}$ of $0.5 \mathrm{~N} \mathrm{NaOH}$. The tissue slides were observed at $550 \mathrm{~nm}$. 

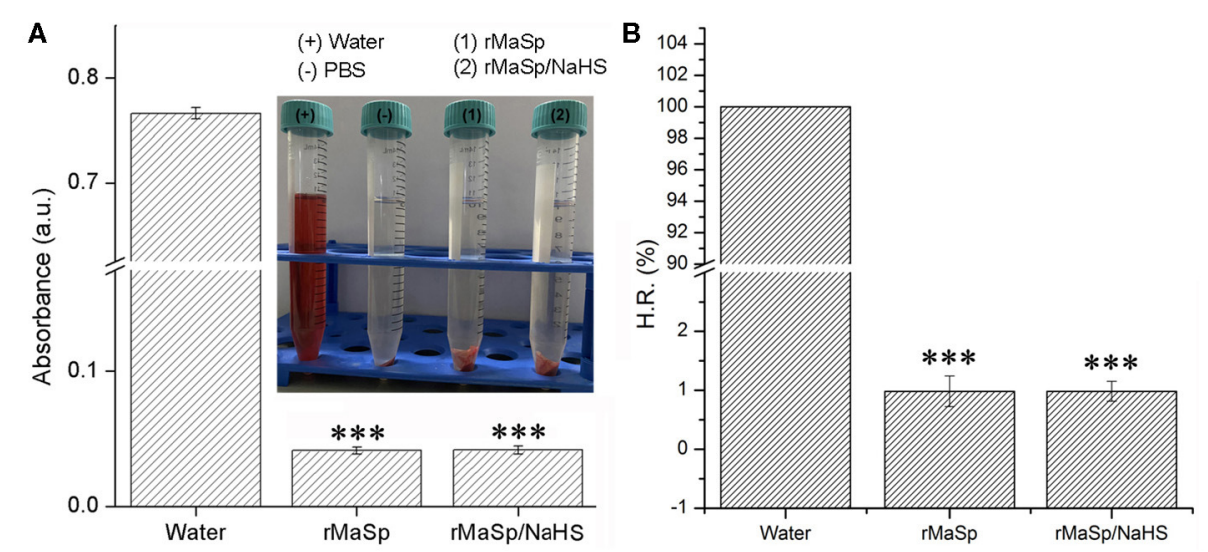

FIGURE 4 | Hemolysis assays of rMaSp membrane and rMaSp/NaHS membrane. (A) The absorbance of each group in hemolysis assays was tested by the use of an absorbance photometer and (B) the hemolysis rate of rMaSp membrane and rMaSp/NaHS membrane. ${ }^{* \star *} p<0.001$ compared to control group, $n=6$.

\section{Statistical Analysis}

All data were expressed as mean $\pm \mathrm{SD}$. The statistical differences were performed using one-way ANOVA followed by Tukey's test with GraphPad Prism 6 software (GraphPad Software Inc., La Jolla, CA, USA). For all tests, ${ }^{*}$ indicates $p$ value $<0.05,{ }^{* *} p$ value $<0.01$, and ${ }^{* * *} p$ value $<0.001$

\section{RESULTS}

\section{Preparation and Characterization of Nanofibrous Membrane}

The recombinant spider silk protein, rMaSp, consists of six units containing two polyalanine and glycine-rich repeated regions from MaSp1 of E. australis. Its molecular weight is $50 \mathrm{kDa}$, and the amino acid sequence is listed in Supplementary Figure 1. rMaSp was successfully expressed in E. coli BL (21DE3) cells and purified with an affinity chromatography processing. The result of Coomassie Brilliant Blue staining (Figure 1A) showed that the purity of the interested protein was above $95 \%$.

According to the characteristics of compatibility (Supplementary Figure 2), porosity (Supplementary Figure 3), and water vapor transmission rate (WVTR) (Supplementary Figure 4) of EPCs, the protein solution spinning system with different concentrations of NaHS was screened, and the protein solution spinning system with $12.5 \mu \mathrm{g} / \mathrm{ml}$ NaHS was finally selected for subsequent experiments. rMaSp and rMaSp blended with NaHS were fabricated into rMaSp membrane and $\mathrm{rMaSp} / \mathrm{NaHS}$ membrane with an electrospinning process as shown in Figure 1B. Figures 2A,C showed the SEM image of rMaSp and $\mathrm{rMaSp} / \mathrm{NaHS}$, Figures 2B,D showed diameter of rMaSp and $\mathrm{rMaSp} / \mathrm{NaHS}$. According to the results, both rMaSp and rMaSp/NaHS generated smooth nanofibers. The diameters of $\mathrm{rMaSp}$ and $\mathrm{rMaSp} / \mathrm{NaHS}$ were $381 \pm 62 \mathrm{~nm}$ and $388 \pm$ $64 \mathrm{~nm}$, which were similar to the fibers generated from pure rMaSp solution. The Nicolet 5700 Fourier transform infrared spectrometer was used to analyze the FTIR spectrum of dried

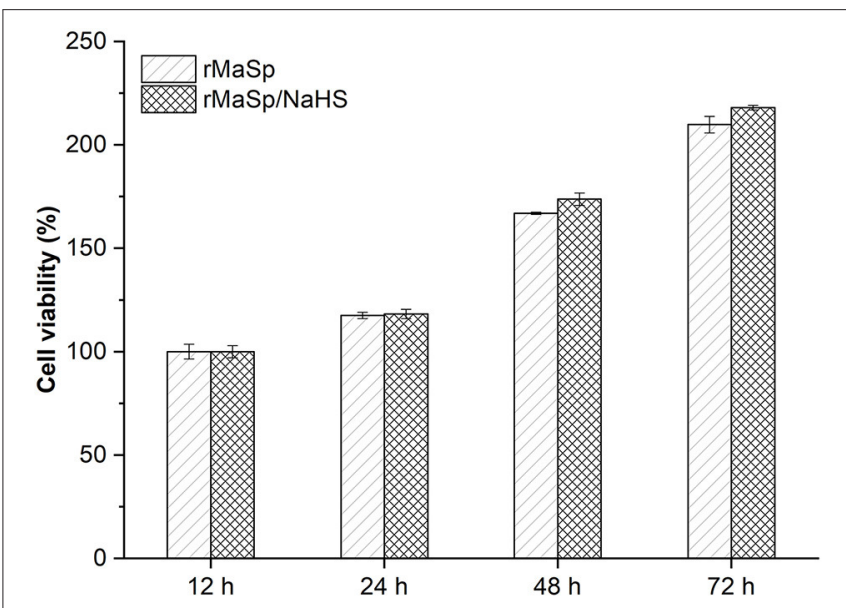

FIGURE 5 | NIH 3T3 cell viability tests when cells were cultured on rMaSp membrane and rMaSp/NaHS membrane for $12-72 \mathrm{~h}$, showing no significant difference in cell viability.

rMaSp membrane and $\mathrm{rMaSp} / \mathrm{NaHS}$ membrane, and the results are shown in Figure 2E.

Figures 2F-I show the mechanical properties of dry and wet membranes. We also found that the stress of membranes dropped and strain increased due to the absorbance of water. Although the water changed the mechanical properties of the membrane, the stress and strain were still in the range of skin mechanical properties (i.e., stress 5-30 MPa, strain 35-115\%).

The wettability has been reported to have great influences on the initial adhesion and proliferation of cells (Birky, 1989; Wei et al., 2009). The dynamic water contact angle was visualized to measure the hydrophilicity. The water droplets on the membrane surfaces were shown in Figures 2J, $\mathbf{K}$. Both the membranes of $\mathrm{rMaSp}$ and $\mathrm{rMaSp} / \mathrm{NaHS}$ showed a hydrophobic surface with the water angle of 20.07 and 21.26, respectively. The swelling capacity of $\mathrm{rMaSp}$ and $\mathrm{rMaSp} / \mathrm{NaHS}$ 

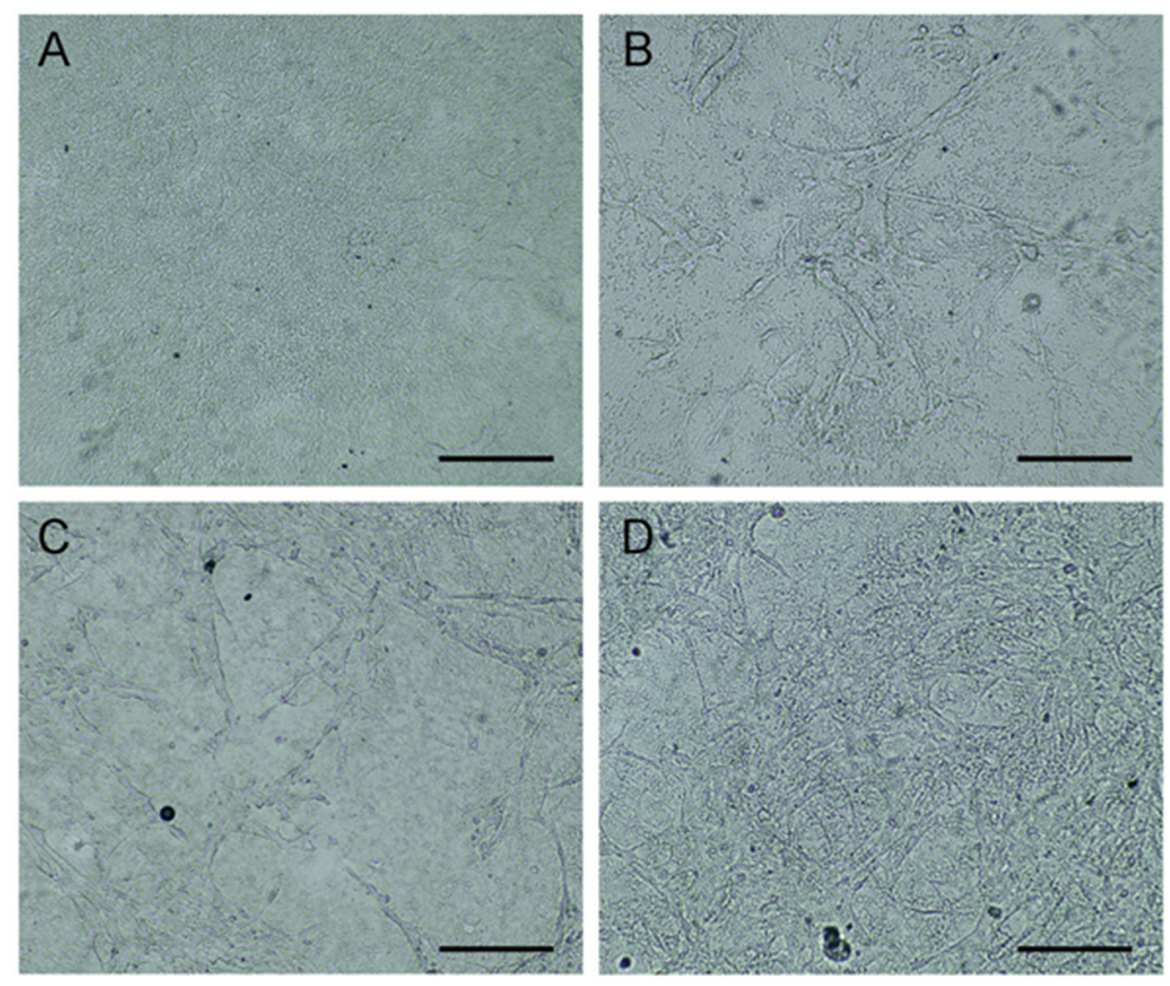

FIGURE 6 | Endothelial progenitor cells (EPCs) cultured on rMaSp/NaHS membrane till the density of 90\%. (A) Optical microphotographs of rMaSp/NaHS membrane. (B-D) EPCs cultured on rMaSp/NaHS membrane on days 1, 3, and 7, respectively.

membranes is shown in Figure $\mathbf{2} \mathbf{L}$, and the results revealed that the swelling capacity of $\mathrm{rMaSp}$ membrane was similar to that of $\mathrm{rMaSp} / \mathrm{NaHS}$ membrane at $\mathrm{pH} 6.0$ and $\mathrm{pH} 7.4 \mathrm{PBS}$ buffer, respectively. The degradation profiles of rMaSp and $\mathrm{rMaSp} / \mathrm{NaHS}$ membranes were shown in Figure 2M, and the degradation of rMaSp membrane at $\mathrm{pH} 6.0$ and $\mathrm{pH} 7.4$ was similar to that of $\mathrm{rMaSp} / \mathrm{NaHS}$ membrane at $\mathrm{pH}$ 7.4. However, the $\mathrm{rMaSp} / \mathrm{NaHS}$ membrane at $\mathrm{pH} 6.0$ has a relatively faster degradation rate, and this may be because of the faster $\mathrm{H}_{2} \mathrm{~S}$ release rate.

\section{Sustained-Release Profile of $\mathrm{H}_{2} \mathrm{~S}$}

Hydrogen sulfide has been identified as the third member of the gasotransmitter, and it plays an essential physiological role in regulating the cytoprotective signal process (Shatalin et al., 2011). Under physiological environments, NaHS quickly reacts with water and releases $\mathrm{H}_{2} \mathrm{~S}$ to elicit physiological responses; however, the short half-life of $\mathrm{H}_{2} \mathrm{~S}$ limits its therapeutic potential (Kashfi and Olson, 2013). It would be a promising therapeutic strategy in biomedical applications to fabricate biocompatible scaffolds releasing $\mathrm{H}_{2} \mathrm{~S}$ in a controlled manner. The releasing kinetics of $\mathrm{H}_{2} \mathrm{~S}$ from the $\mathrm{rMaSp} / \mathrm{NaHS}$ nanofibrous membrane (with 10\% NaHS) was performed under $\mathrm{pH} 7.4$ with NaHS in solution as the control. Longer-term and shortterm releasing profiles $(0-28,800 \mathrm{~min})$ are shown in Figure 3. The curve of NaHS showed a burst release of $\mathrm{H}_{2} \mathrm{~S}$ within
$3 \mathrm{~h}$. That is because, upon hydrolysis, NaHS dissociated and rapidly generated a large amount of $\mathrm{H}_{2} \mathrm{~S}$, leading to an instantaneously maximum concentration of $\mathrm{H}_{2} \mathrm{~S}$ and then exponentially falling thereafter, likely owing to $\mathrm{H}_{2} \mathrm{~S}$ loss from solution via volatilization and $\mathrm{H}_{2} \mathrm{~S}$ oxidation in the physiological buffer (Lin et al., 2017). Unlike the releasing kinetics of NaHS donor in solution, the $\mathrm{rMaSp} / \mathrm{NaHS}$ membrane showed a very mild burst of $\mathrm{H}_{2} \mathrm{~S}$ with low concentration within $8 \mathrm{~h}$, followed by a prolonged duration for $48 \mathrm{~h}$. The instantaneous concentration of $\mathrm{H}_{2} \mathrm{~S}$ was around $9 \mu \mathrm{M}$, which was covered in the range of 2-10 $\mu \mathrm{M}$, the endogenous $\mathrm{H}_{2} \mathrm{~S}$ plasma concentrations in healthy animals (Whitfield et al., 2008; Shen et al., 2011). The analytical results show that, by employing $\mathrm{rMaSp}$, the duration of $\mathrm{H}_{2} \mathrm{~S}$ release can be prolonged, increasing the potential applications.

\section{Biocompatibility of Nanofibrous Membrane}

Hemocompatibility and cytocompatibility of biomaterials codetermine the success of tissue engineering applications (Stoll et al., 2017). The results of hemolysis assays are shown in Figure 4, and the hemolysis rate of rMaSp membrane and $\mathrm{rMaSp} / \mathrm{NaHS}$ membrane is 0.96 and $1.00 \%$, respectively, which is far lower than 5\%, demonstrating excellent hemocompatibility.

NIH 3T3 cells were cultured on the membranes for $72 \mathrm{~h}$ to investigate the cytocompatibility of $\mathrm{rMaSp}$ and $\mathrm{rMaSp} / \mathrm{NaHS}$ 


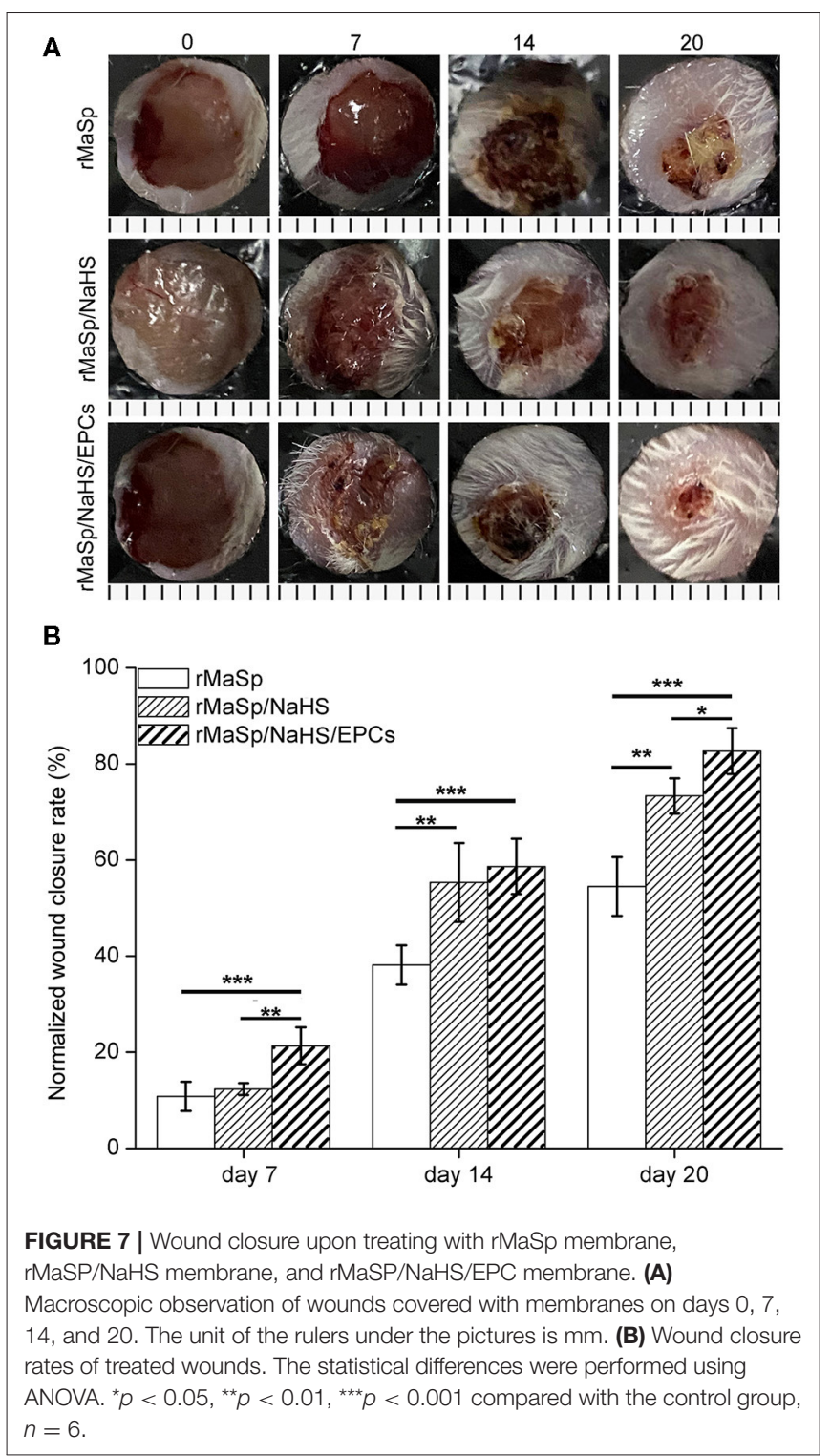

membranes. Figure $\mathbf{5}$ shows that there is no significant difference in cell viability between the cells cultured on rMaSp membrane and $\mathrm{rMaSp} / \mathrm{NaHS}$ membrane at each time point. Previous studies demonstrated that the rMaSp/NaHS membrane was non-toxic to fibroblast cells, which is essential for the wound healing process (Schacht et al., 2015). The RMaSp/NAHS membrane was assumed to maintain its capacity to support fibroblast cell proliferation in vivo.

\section{Endothelial Progenitor Cells Cultured on rMaSp/NaHS Membrane}

Endothelial progenitor cells have been found that they can be used to enhance wound healing (Kim et al., 2009; Asai et al., 2013). In this study, EPCs were cultured on the rMaSp/NaHS membrane to form a novel wound dressing, rMaSp/NaHS/EPCs. Figure 6 shows the optical microphotographs of EPCs cultured on the rMaSp/NaHS membrane to the density of $90 \%$ within 7 days.

\section{In vivo Wound Healing}

The wound healing efficacy of this novel $\mathrm{H}_{2} \mathrm{~S}$ releasing and EPCloaded nanofibrous membrane was evaluated by performing in vivo experiments on animal models. Full-thickness removal skin caused by cutaneous wounds in male BALB/c mice was established to study the wound healing capability. The wound healing progress was analyzed at different time points during 20 days after transplantation. Figure 7A shows the sequential macroscopic images of full-thickness models treated with $\mathrm{rMaSp}$, $\mathrm{rMaSp} / \mathrm{NaHS}$, and $\mathrm{rMaSp} / \mathrm{NaHS} / \mathrm{EPC}$ nanofibrous membranes after days 7,14 , and 20, respectively. It can be seen that wounds were gradually regenerated from the edge of wound. Compared with the rMaSp membrane, rMaSp/NaHS/EPCtreated wounds showed enhanced wound closure at each time point, while the $\mathrm{rMaSp} / \mathrm{NaHS}$ membrane-treated wounds were enhanced after 7-day treatment. These different results between $\mathrm{rMaSp} / \mathrm{NaHS}$ membrane and $\mathrm{rMaSp} / \mathrm{NaHS} / \mathrm{EPC}$ suggested the positive function of the $\mathrm{rMaSp} / \mathrm{NaHS} / \mathrm{EPC}$ dressing likely due to the $\mathrm{H}_{2} \mathrm{~S}$ releasing together with the loading EPCs. Figure 7B shows the quantitatively calculated wound closure rates for rMaSp-, rMaSp/NaHS-, and rMaSp/NaHS/EPC-treated wounds. Consistent with the visual macroscopic images of wounds, the healing rate of $\mathrm{rMaSp} / \mathrm{NaHS} / \mathrm{EPC}$-treated group was significantly higher than that of $\mathrm{rMaSp}$ and $\mathrm{rMaSp} / \mathrm{NaHS}$ at all the time points studied (day 7, 10,14, and 17). Especially at day 20, the final closure rate for $\mathrm{rMaSp} / \mathrm{NaHS} / \mathrm{EPC}$-treated group was 28, 9\% faster than rMaSp- and $\mathrm{rMaSp} / \mathrm{NaHS}$-treated wounds, with a wound closure rate of $82.7 \pm 4.8 \%$ in contrast to 54.5 \pm 6.1 and $73.3 \pm 3.7 \%$. Both the macroscopic observation and quantified wound closure rate revealed that the healing of the wound was significantly improved under treatment with $\mathrm{H}_{2} \mathrm{~S}$ releasing fibers together with loaded EPCs compared with only $\mathrm{H}_{2} \mathrm{~S}$ releasing fibers.

Cutaneous wound healing in adult mammals is a complex multistep process involving overlapping stages of blood clot formation, inflammation, reepithelialization, granulation tissue formation, neovascularization, and remodeling. As shown in Figure 8, the representative H\&E staining histological images of granulation tissue are used to evaluate wound healing; Compared to rMaSp group, rMaSp/NaHS could get better regeneration of skin wound in mice, which may be due to slowly releasing of the H2S. Additionally, EPCs could promote angiogenesis in the wound, which has been supported by the histopathologic analysis. As shown in Figure 8, the effect of $\mathrm{rMaSp} / \mathrm{NaSH} / \mathrm{EPCs}$ promoting tissue regeneration was significantly higher than that of the other two groups, and the histopathologic analysis also supported these findings. The underlying dermis and other subcutaneous tissue were infiltrated by abundant granulation tissue. The complete and thick epidermis was seen in the $\mathrm{rMaSp} / \mathrm{NaHS} / \mathrm{EPC}$-treated defects on day 21 in H\&E staining images.

Matrical collagen deposition upon post wound was quantitatively evaluated on day 7 and day 20. Figure 9 depicts the detection results of collagen deposition in regenerated 


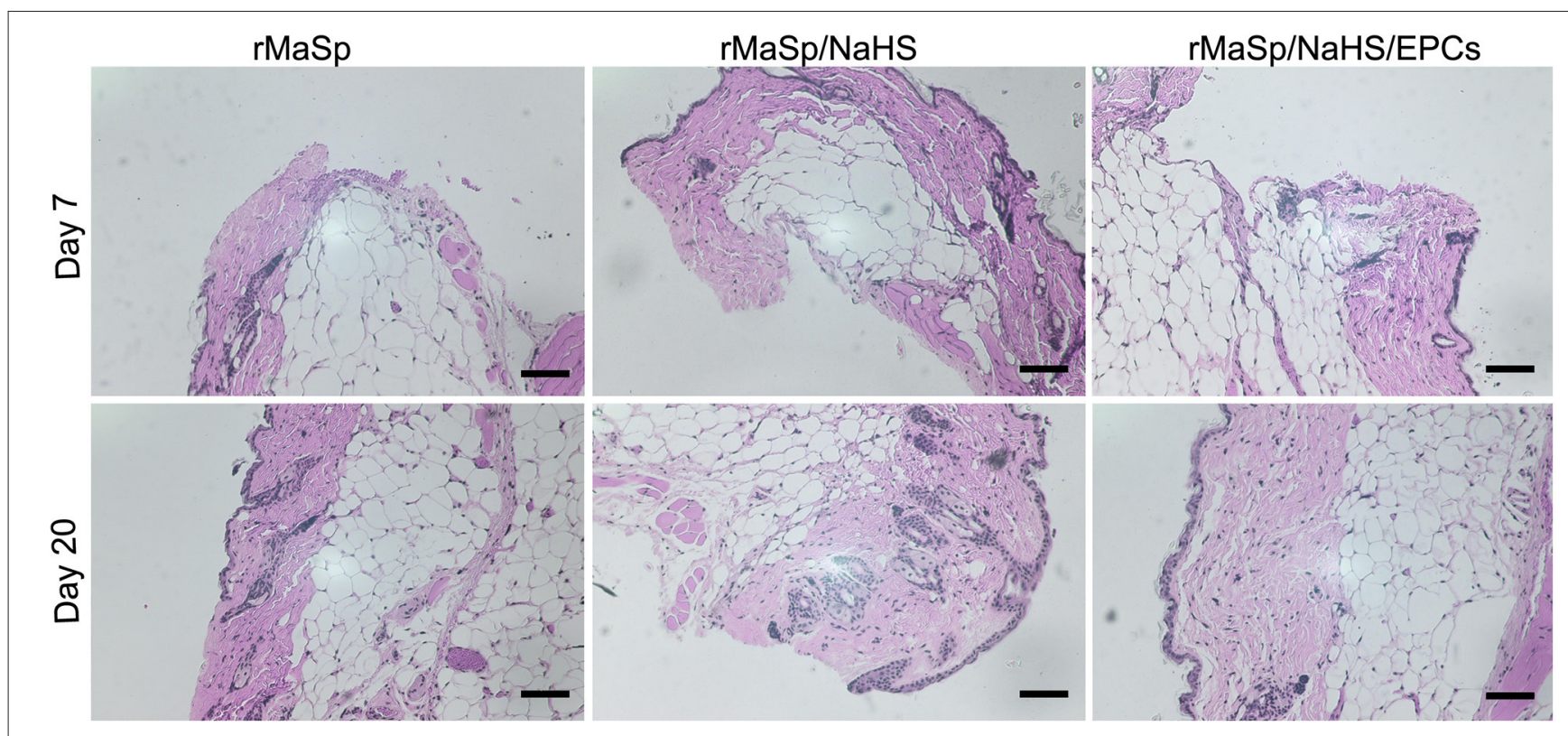

FIGURE 8 | Hematoxylin and eosin (HandE) staining of wound site on days 7 and 20. Quantified granulation formation calculated from HandE staining on RMASP vs. RMASP-JK1 on days 7 and 20. Quantified reepithelization calculated from cytokeratin staining on RMASP vs. RMASP-JK1 on days 7 and 20 . The statistical differences were performed using ANOVA. ${ }^{* *} p<0.01,{ }^{\star} p<0.05$ compared with the RMASP group, $n>3$. The scale bar is $500 \mu \mathrm{m}$.

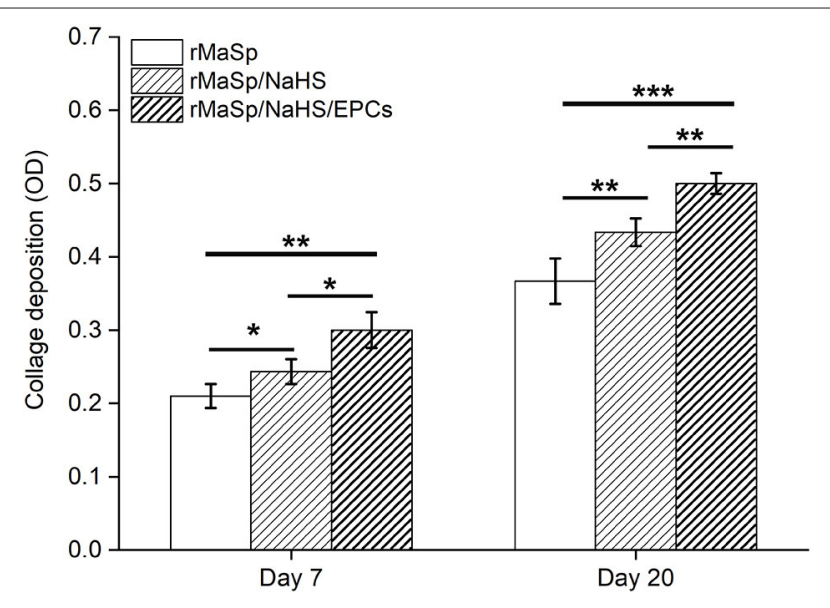

FIGURE 9 | Collagen deposition upon post wound detected on days 7 and 20. ${ }^{\star} p<0.05,{ }^{* *} p<0.01,{ }^{* \star *} p<0.001$ compared with the control group, $n=6$.

skin at indicated time intervals. Deposition of collagen in rMaSp/NaHS-treated group and rMaSp/NaHS/EPCs-treated group is significantly higher than in $\mathrm{rMaSp}$-treated group on both days 7 and 20. The deposition of collagen in rMaSp/NaHS/EPCtreated group is significantly higher than in $\mathrm{rMaSp} / \mathrm{NaHS}$-treated group. The results indicated that sustained releasing of $\mathrm{H}_{2} \mathrm{~S}$ from nanofibers together with loading EPCs obviously enhanced neo-tissue formation.

\section{DISCUSSION}

Skin is the largest organ of the human body, which plays an important role as a barrier in protecting the body from the surrounding environment (Barros Almeida et al., 2021). The development of skin dressings to replace normal human skin is of great significance to the repair of human skin injury, where the dressings not only can protect the wound but also add the growth factor and other components to the skin dressing to promote wound healing (Yildirimer et al., 2012). Many studies reported that EPCs were recruited into injured tissues and contributed to neovessel formation by directly incorporating into vessel walls or by secreting a variety of angiogenic growth factors and subsequently stimulating angiogenesis (Rehman et al., 2003); both angiogenesis and vasculogenesis may play major roles in the process of neovascularization during adult wound healing (Kaushik and Das, 2019); and studies reported that EPCs were used to enhance the wound healing as seeding cell in tissue engineering (Kim et al., 2009; Asai et al., 2013). Maintaining the cell activity of EPCs is one of the key issues while repairing skin injury based on EPCs. Many studies verified that $\mathrm{H}_{2} \mathrm{~S}$ is a potential gasotransmitter upon wound regeneration as it could promote proliferation and migration of EPCs, and meanwhile, $\mathrm{H}_{2} \mathrm{~S}$ can promote microvessel tube formation as well as angiogenesis through the vascular endothelial growth factor receptor-2 (VEGF-2) pathway (Papapetropoulos et al., 2009; Coletta et al., 2012). NaHS has been widely used as the $\mathrm{H}_{2} \mathrm{~S}$ donor (Kashfi and Olson, 2013), but the shortterm burst from $\mathrm{NaHS}$ and short half-life of $\mathrm{H}_{2} \mathrm{~S}$ hindered the application of NaHS, and it is necessary to prepare a biocompatible carrier that can release $\mathrm{NaHS}$ and $\mathrm{H}_{2} \mathrm{~S}$ in a slow and prolonged manner.

In this study, a nanofibrous membrane, which is prepared by using recombinant spider silk protein ( $\mathrm{rMaSp}$ ) and NaHS, was contrasted by the use of electrospun. According to the results, the $\mathrm{rMaSp} / \mathrm{NaHS} / \mathrm{EPC}$ membrane prepared in this study has good biocompatibility and good mechanical strength. The in vivo experiment showed that it could adhere to 
the wound evenly and tightly for at least 3 weeks. The $\mathrm{rMaSp} / \mathrm{NaHS} / \mathrm{EPC}$ membrane not only can prevent bacteria from passing through but also has good air permeability. It can also release $\mathrm{H}_{2} \mathrm{~S}$ stably for a long time. After loaded with EPCs, $\mathrm{rMaSp} / \mathrm{NaHS} / \mathrm{EPC}$ membrane was used as a wound dressing in a cutaneous wound model in vivo. The results showed that $\mathrm{rMaSp} / \mathrm{NaHS} / \mathrm{EPC}$ membrane could significantly enhance the wound regeneration compared with rMaSp membrane and $\mathrm{rMaSp} / \mathrm{NaHS}$ membrane. Those results indicated that $\mathrm{rMaSp} / \mathrm{NaHS} / \mathrm{EPC}$ membrane wound dressing prepared in this study has a broad application prospect in the field of skin tissue regeneration.

\section{CONCLUSIONS}

In this study, a novel wound dressing $\mathrm{rMaSp} / \mathrm{NaHS} / \mathrm{EPC}$ was designed, and its efficacy of wound healing was evaluated by using in vivo experiments. This study demonstrated that rMaSp/NaHS/EPCs could promote wound healing efficiency through $\mathrm{H}_{2} \mathrm{~S}$ and EPCs. This study mainly focused on the effects of the constructed membrane structure on the proliferation of EPCs, the release properties of $\mathrm{H}_{2} \mathrm{~S}$, and the repair of skin injury in mice. The antibacterial properties and anti-inflammatory of the membrane are the limitations in this study, and they will be discussed in our future studies.

\section{REFERENCES}

Altaany, Z., Yang, G., and Wang, R. (2013). Crosstalk between hydrogen sulfide and nitric oxide in endothelial cells. J. Cell. Mol. Med. 17, 879-888. doi: $10.1111 /$ jcmm.12077

Andersson, M., Jia, Q., Abella, A., Lee, X., Landreh, M., Purhonen, P., et al. (2017). Biomimetic spinning of artificial spider silk from a chimeric minispidroin. Nat. Chem. Biol. 13, 262-264. doi: 10.1038/nchembio.2269

Asahara, T., Murohara, T., Sullivan, A., Silver, M., van der Zee, R., Li, T., et al. (1997). Isolation of putative progenitor endothelial cells for angiogenesis. Science 275, 964-967. doi: 10.1126/science.275.5302.964

Asai, J., Takenaka, H., Ii, M., Asahi, M., Kishimoto, S., Katoh, N., et al. (2013). Topical application of ex vivo expanded endothelial progenitor cells promotes vascularisation and wound healing in diabetic mice. Int. Wound J. 10, 527-533. doi: 10.1111/j.1742-481X.2012.01010.x

Baklaushev, V., Bogush, V., Kalsin, V., Sovetnikov, N., Samoilova, E., Revkova, V., et al. (2019). Tissue engineered neural constructs composed of neural precursor cells, recombinant spidroin and PRP for neural tissue regeneration. Sci. Rep. 9:3161. doi: 10.1038/s41598-019-39341-9

Barros Almeida, I., Garcez Barretto Teixeira, L., Oliveira de Carvalho, F., Ramos Silva, É., Santos Nunes, P., Viana Dos Santos, M., et al. (2021). Smart Dressings for Wound Healing: A Review. Adv. Skin Wound Care 34, 1-8. doi: 10.1097/01.ASW.0000725188.95109.68

Birky, C. (1989). Organelle evolution. Genome 31, 1095-1097. doi: $10.1139 / g 89-192$

Coletta, C., Papapetropoulos, A., Erdelyi, K., Olah, G., Módis, K., Panopoulos, P., et al. (2012). Hydrogen sulfide and nitric oxide are mutually dependent in the regulation of angiogenesis and endothelium-dependent vasorelaxation. Proc. Natl. Acad. Sci. U. S. A. 109, 9161-9166. doi: 10.1073/pnas.12029 16109

Feng, S., Zhao, Y., Xian, M., and Wang, Q. (2015). Biological thiols-triggered hydrogen sulfide releasing microfibers for tissue engineering applications. Acta Biomater. 27, 205-213. doi: 10.1016/j.actbio.2015.09.010

Hong, Y., Huber, A., Takanari, K., Amoroso, N., Hashizume, R., Badylak, S., et al. (2011). Mechanical properties and in vivo behavior of a biodegradable

\section{DATA AVAILABILITY STATEMENT}

The original contributions presented in the study are included in the article/Supplementary Material, further inquiries can be directed to the corresponding authors.

\section{ETHICS STATEMENT}

The animal study was reviewed and approved by the Ethical Board of Shanghai Ninth People's Hospital.

\section{AUTHOR CONTRIBUTIONS}

JL and GJ designed the research and performed the experiments. $\mathrm{XC}$ and YCai interpreted the results of the experiments. CL analyzed the data and prepared figures. SM and YCao designed the experiments, provided the experimental insight, and edited the manuscript. All authors read and approved the final manuscript.

\section{SUPPLEMENTARY MATERIAL}

The Supplementary Material for this article can be found online at: https://www.frontiersin.org/articles/10.3389/fbioe. 2021.657549/full\#supplementary-material

synthetic polymer microfiber-extracellular matrix hydrogel biohybrid scaffold. Biomaterials 32, 3387-3394. doi: 10.1016/j.biomaterials.2011.01.025

Kashfi, K., and Olson, K. (2013). Biology and therapeutic potential of hydrogen sulfide and hydrogen sulfide-releasing chimeras. Biochem. Pharmacol. 85, 689-703. doi: 10.1016/j.bcp.2012.10.019

Kaushik, K., and Das, A. (2019). Endothelial progenitor cell therapy for chronic wound tissue regeneration. Cytotherapy 21, 1137-1150. doi: 10.1016/j.jcyt.2019.09.002

Kim, K., Han, D., Park, K., Song, S., Kim, J., Kim, J., et al. (2009). Enhanced dermal wound neovascularization by targeted delivery of endothelial progenitor cells using an RGD-g-PLLA scaffold. Biomaterials 30, 3742-3748. doi: 10.1016/j.biomaterials.2009.03.053

Lin, W.-C., Huang, C.-C., Lin, S.-J., Li, M.-J., Chang, Y., Lin, Y.-J., et al. (2017). In situ depot comprising phase-change materials that can sustainably release a gasotransmitter H2S to treat diabetic wounds. Biomaterials 145, 1-8. doi: 10.1016/j.biomaterials.2017.08.023

Lin, Y., Weisdorf, D., Solovey, A., and Hebbel, R. (2000). Origins of circulating endothelial cells and endothelial outgrowth from blood. J. Clin. Invest. 105, 71-77. doi: 10.1172/JCI8071

Omenetto, F., and Kaplan, D. (2010). New opportunities for an ancient material. Science 329, 528-531. doi: 10.1126/science.1188936

Papapetropoulos, A., Pyriochou, A., Altaany, Z., Yang, G., Marazioti, A., Zhou, Z., et al. (2009). Hydrogen sulfide is an endogenous stimulator of angiogenesis. Proc. Natl. Acad. Sci. U. S. A. 106, 21972-21977. doi: 10.1073/pnas.0908047106

Paul, B., and Snyder, S. (2015). H2S: a novel gasotransmitter that signals by sulfhydration. Trends Biochem. Sci. 40, 687-700. doi: 10.1016/j.tibs.2015.08.007

Putzu, M., Causa, F., Parente, M., González de Torre, I., Rodriguez-Cabello, J., and Netti, P. (2019). Silk-ELR co-recombinamer covered stents obtained by electrospinning. Regen. Biomater. 6, 21-28. doi: 10.1093/rb/rby022

Rehman, J., Li, J., Orschell, C., and March, K. (2003). Peripheral blood "endothelial progenitor cells" are derived from monocyte/macrophages and secrete angiogenic growth factors. Circulation 107, 1164-1169. doi: 10.1161/01.CIR.0000058702.69484.A0

Resch, A., Wolf, S., Mann, A., Weiss, T., Stetco, A., and Radtke, C. (2018). Coculturing human adipose derived stem cells and Schwann cells on spider silk-a 
new approach as prerequisite for enhanced nerve regeneration. Int. J. Mol. Sci. 20:10071. doi: 10.3390/ijms20010071

Schacht, K., Jüngst, T., Schweinlin, M., Ewald, A., Groll, J., and Scheibel, T. (2015). Biofabrication of cell-loaded 3D spider silk constructs. Angew. Chem. 54, 2816-2820. doi: 10.1002/anie.201409846

Shatalin, K., Shatalina, E., Mironov, A., and Nudler, E. (2011). H2S: a universal defense against antibiotics in bacteria. Science 334, 986-990. doi: 10.1126/science.1209855

Shen, X., Pattillo, C., Pardue, S., Bir, S., Wang, R., and Kevil, C. (2011). Measurement of plasma hydrogen sulfide in vivo and in vitro. Free Rad. Biol. Med. 50, 1021-1031. doi: 10.1016/j.freeradbiomed.2011.01.025

Stoll, H., Steinle, H., Stang, K., Kunnakattu, S., Scheideler, L., Neumann, B., et al. (2017). Generation of large-scale DNA hydrogels with excellent blood and cell compatibility. Macromol. Biosci. 17:252. doi: 10.1002/mabi.201600252

Wallace, J., Vong, L., McKnight, W., Dicay, M., and Martin, G. (2009). Endogenous and exogenous hydrogen sulfide promotes resolution of colitis in rats. Gastroenterology 137, 569-578. doi: 10.1053/j.gastro.2009.04.012

Wei, J., Igarashi, T., Okumori, N., Maetani, T., Liu, B., and Yoshinari, M. (2009). Influence of surface wettability on competitive protein adsorption and initial attachment of osteoblasts. Biomed. Mater. 4:045002. doi: 10.1088/1748-6041/4/4/045002

Whitfield, N., Kreimier, E., Verdial, F., Skovgaard, N., and Olson, K. (2008). Reappraisal of H2S/sulfide concentration in vertebrate blood and its potential significance in ischemic preconditioning and vascular signaling. Am. J. Physiol. Regul. Integr. Comp. Physiol. 294, R1930-R1937. doi: 10.1152/ajpregu.00025.2008

Wirohadidjojo, Y., Radiono, S., Budiyanto, A., and Soebono, H. (2011). Cellular viability, collagen deposition, and transforming growth factor $\beta 1$ production among ultraviolet B-irradiated keloid fibroblasts. Aesthetic Plast. Surg. 35 1050-1055. doi: 10.1007/s00266-011-9732-X

Wu, J., Li, Y., He, C., Kang, J., Ye, J., Xiao, Z., et al. (2016). Novel H2S releasing nanofibrous coating for in vivo dermal wound regeneration. ACS Appl. Mater. Interfaces 8, 27474-27481. doi: 10.1021/acsami.6b 06466

Yildirimer, L., Thanh, N., and Seifalian, A. (2012). Skin regeneration scaffolds: a multimodal bottom-up approach. Trends Biotechnol. 30, 638-648. doi: $10.1016 /$ j.tibtech.2012.08.004

Conflict of Interest: The authors declare that the research was conducted in the absence of any commercial or financial relationships that could be construed as a potential conflict of interest.

Publisher's Note: All claims expressed in this article are solely those of the authors and do not necessarily represent those of their affiliated organizations, or those of the publisher, the editors and the reviewers. Any product that may be evaluated in this article, or claim that may be made by its manufacturer, is not guaranteed or endorsed by the publisher.

Copyright (C) $2021 \mathrm{Lian}, \mathrm{Ju}, \mathrm{Cai}, \mathrm{Cai}, \mathrm{Li}, \mathrm{Ma}$ and Cao. This is an open-access article distributed under the terms of the Creative Commons Attribution License (CC BY). The use, distribution or reproduction in other forums is permitted, provided the original author(s) and the copyright owner(s) are credited and that the original publication in this journal is cited, in accordance with accepted academic practice. No use, distribution or reproduction is permitted which does not comply with these terms. 